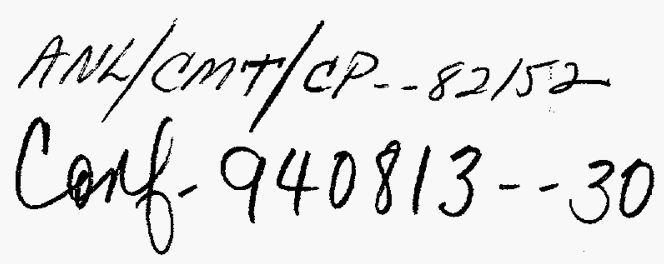

\title{
ACTINIDE SEPARATION OF HIGH-LEVEL WASTE USING SOLVENT EXTRACTANTS ON MAGNETIC MICROPARTICLES
}

\author{
by
}

L. Nuñez, B. A. Buchholz, M. Kaminski, S. B. Aase

N. R. Brown, and G. F. Vandegrift

Chemical Technology Division

Argonne National Laboratory

9700 South Cass Ave

Argonne, Illinois 60439-4837

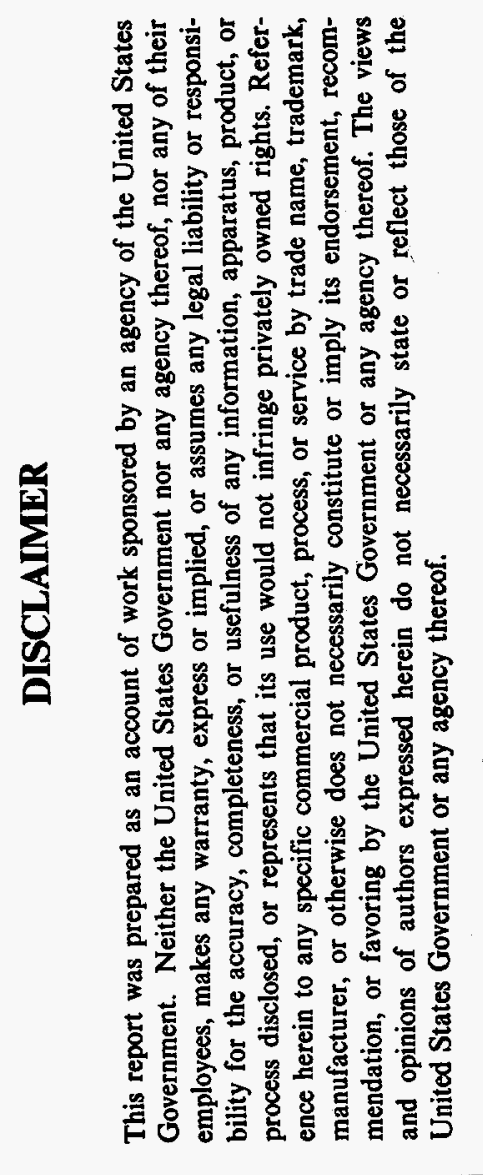

Proceeding for:

ACS Symposium

Washington, DC

August 22-26, 1994

The submitted manuscript has been authored by a
contractor of the U. S. Government under contract No.
W-31-109-ENG-38. Accordingly, the U. S. Government
retains a nonexclusive, royalty-free license to publish
or reproduce the published form of this contribution, or
allow others to do so, for U.S. Government purposes. 


\section{DISCLAIMER}

Portions of this document may be illegible in electronic image products. Images are produced from the best available original document. 


\title{
ACTINIDE SEPARATION OF HIGH-LEVEL WASTE USING SOLVENT EXTRACTANTS ON MAGNETIC MICROPARTICLES
}

\author{
L. Nuñez, B. A. Buchholz, M. Kaminski, S. B. Aase, \\ N. R. Brown, and G. F. Vandegrift \\ Chemical Technology Division \\ Argonne National Laboratory \\ 9700 S. Cass Avenue \\ Argonne, IL 60439
}

\begin{abstract}
Polymeric-coated ferromagnetic particles with an absorbed layer of octyl(phenyl)$\mathrm{N}, \mathrm{N}$-diisobutylcarbamoylmethylphosphine oxide (CMPO) diluted by tributyl phosphate (TBP) are being evaluated for application in the separation and the recovery of low concentrations of americium and plutonium from nuclear waste solutions. Due to their chemical nature, these extractants selectively complex americium and plutonium contaminants onto the particles, which can be recovered from the waste solution using a magnet. The effectiveness of the extractant-absorbed particles at removing transuranics (TRU) from simulated solutions and various nitric acid solutions was measured by gamma and liquid scintillation counting of plutonium and americium. The $\mathrm{HNO}_{3}$ concentration range was $0.01 \mathrm{M}$ to $6 \mathrm{M}$. The partition coefficients $\left(\mathrm{K}_{\mathrm{d}}\right)$ for various actinides at $2 \mathrm{M} \mathrm{HNO}_{3}$ were determined to be between 3000 and 30,000. These values are larger than those projected for TRU recovery by traditional liquid/liquid extraction. Results from transmission electron microscopy indicated a large dependence of $\mathrm{K}_{\mathrm{d}}$ on relative magnetite location within the polymer and the polymer surface area. Energy disperse spectroscopy demonstrated homogeneous metal complexation on the polymer surface with no metal clustering. The radiolytic stability of the particles was determined by using ${ }^{60} \mathrm{Co}$ gamma irradiation under various conditions. The results showed that $\mathrm{K}_{\mathrm{d}}$ more strongly depends on the nitric acid dissolution rate of the magnetite than the gamma irradiation dose. Results of actinide separation from simulated high-level waste representative of that at various DOE sites are also discussed.
\end{abstract}

\section{Introduction}

One of the remediation activities for high-level waste (HLW) contained in underground storage tanks at Hanford and other Department of Energy (DOE) sites focuses on the separation of actinides. Solvent extraction is one of the separation processes used for removing actinides from 
HLW. These processes use selective extractants such as tributyl phosphate (TBP) and octyl(phenyl)-N,N-disobutylcarbamoylmethylphosphine oxide (CMPO) for actinide separation. 1-4 In addition to chemical separation capabilities, potential technologies for HLW cleanup efforts at Hanford are likely to require compact operation and cost-effective application.5 With both remediation and regulatory goals in mind, we are developing magnetically assisted chemical separation (MACS) processes. The processes use polymer-embedded ferromagnetic particles coated with an organic-complexant-containing solvent for selective separation of actinides. The greatest benefit of this technology is the simple separation of radionuclides from liquid waste in a cost-efficient and compact process without the production of large secondary waste streams.

This paper reports on the development of the MACS separation process in the following areas: (1) design of a magnetically stabilized fluidized-bed system, (2) separation capabilities of tracer actinides from simulated HLW solutions from various DOE sites, (3) gamma-irradiation effects on the microparticles, and (4) particle-coating durability under gamma irradiation. The experimental findings include high separation capabilities for americium and plutonium from many HLW streams, with performance superior to that expected from traditional solvent extraction. Gamma irradiation on both the polymer and the extractants reduces the separation capabilities as a function of increased radiation. Hydrolysis of the coatings in strong nitric acid solutions decreased separation capabilities more than radiation exposure.

\section{Process Description/Design}

The MACS process is described in the literature. 6 A magnetically fluidized bed was recently designed. It is based on the premise that the actinide separation process should minimize mechanical features to reduce maintenance in a compact modular unit. Work has already been

done with magnetically stabilized fluidized beds (MSFB) in chromatographic separations. ${ }^{\mathbf{7 - 8}}$ For these designs, the stabilizing particles are magnetic and flow (with essentially plug flow) across the waste stream to be separated. The differences in sorption equilibria allow for the multicomponent feed stream to separate as the components are passed across the MSFB flow. The stabilizing particles may contain a solid ion exchange media or be coated with liquid sorbents. The MACS process could be adapted to the MSFB concept for extraction and separation of actinides. In that case, the fluidized bed (in preliminary design) would be used to contact ferromagnetic particles coated with organophosphorous extractants with actinide radioisotopes in solution. Figure 1 shows a diagram of the current design for the MACS fluidized bed MSFB. The magnetically fluidized bed would be designed to have a hold-up volume of ten liters and operate in 
a countercurrent fashion. The actinide elements would be extracted by the CMPO/TBP and the magnetic microparticles. Simulants of HLW would be pumped into the bottom of a column to disperse and fluidize the MACS particles throughout the waste.

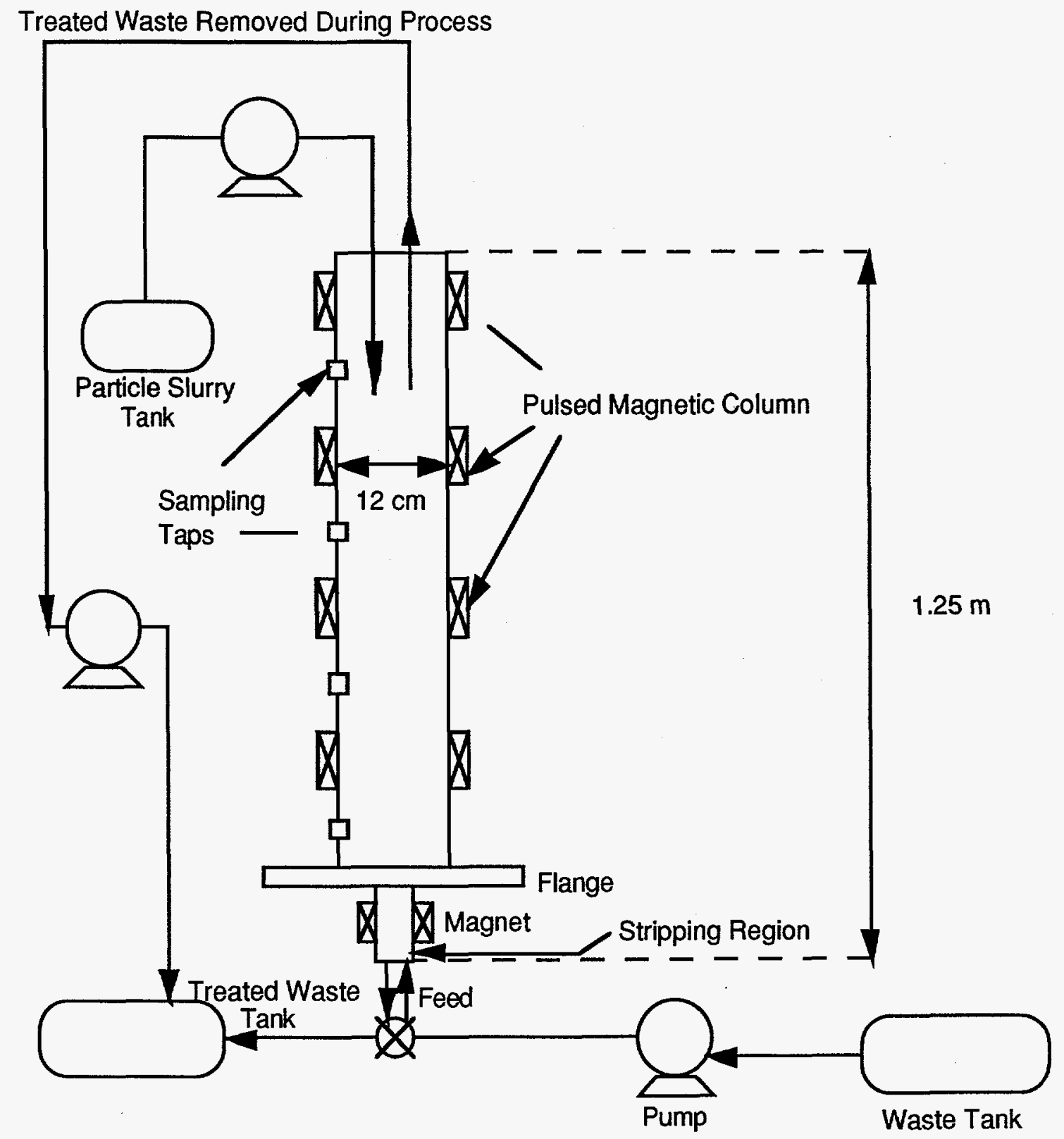

Figure 1. Process Diagram for MACS Fluidized Bed

As shown in Fig. 1, a suspended solution containing the MACS particles will be poured in from the top of the column and continuously moved through the waste solution in the column (multiple stages) using magnetic pulsing and gravity. As the waste fluid flow increases, the upward forces of drag and buoyancy on the particles balance the downward force of gravity. 
Decontaminated waste can be removed from the top of the column. A pump will force more waste into the bottom of the column, fluidizing the particles at the desired height. The magnetic pulsing can continue during the pumping of the waste for complete dispersion of the particles. To pulse the particles in the column, magnetic coils are placed around the outside of the column on a slant so that the particles move along the magnetic lines of force, and the coils can be alternately activated and deactivated to provide vertical motion of the particles in the column.

After adequate contact time or depletion of the supply of waste, the particles settle to the stripping region at the bottom of the column. When the contacting procedure is complete, the particles are separated by a magnet. As much treated waste as possible is removed, and the particles are sent through a stripping process to remove the activity. The particles can then be recycled for further use in extraction.

The Ergun equation ${ }^{9}$ can be used to solve problems involving packed and fluidized beds:

$$
\frac{\Delta P}{l}=\frac{150 \mu V_{o m}}{D_{p}^{2}} \frac{(1-\varepsilon)^{2}}{\varepsilon^{3}}+\frac{1.75 \rho V_{o m}^{2}}{D_{p}} \frac{(1-\varepsilon)}{\varepsilon^{3}}
$$

where

$\Delta \mathrm{P}$ is the pressure drop, in $\mathrm{Pa}$

$l$ is the bed height, in $m$

$\mu$ is the viscosity, in $\mathrm{kg} / \mathrm{m} \cdot \mathrm{s}$

$\mathrm{V}^{\circ \mathrm{m}}$ is the minimum fluidization velocity, in $\mathrm{m} / \mathrm{s}$

$D_{p}$ is the particle diameter, in $m$

$\varepsilon$ is the void fraction of the bed (dimensionless)

$\rho$ is the density of the fluid in the bed, in $\mathrm{kg} / \mathrm{m}^{3}$

The Ergun equation has two separate terms: the first term accounts for mostly laminar flow characteristics, while the second accounts for those resulting from turbulence. For the MACS process, the small size ( $<25$ microns) of the particles means that only laminar flow characteristics will be present (Stokes' Law).

The minimum fluidization velocity was calculated on the basis of the following assumptions: particle diameter of $1-25$ microns and density of $2.5-5.0 \mathrm{~g} / \mathrm{cm}^{3}$, void fraction of 0.1-0.9, and waste stream viscosity and density approximately equal to those of water. The pressure drop and bed height were calculated by varying particle diameter and density over a reasonable range for both these variables. For a typical waste stream, the pressure drop ranged from 5-66 Pa for a bed height of 3.9-1.95 $\mathrm{mm}$.

The MSFB concept contrasts with solvent extraction pulse columns, where the heavier and lighter phases of the mixture collect on contact mesh plates. A fluid pulse forces the phases into contact by pushing one phase through the mesh into contact with the other phase. 


\section{Experimental and Calculational Methods}

Reagents. All the reagents used to prepare the simulant waste were ACS reagent grade. The CMPO was crystallized for purity, 10 and the TBP was obtained from Aldrich Chemical Company (Gold label) and used without further purification. All radioactive tracers were from stock in the Chemical Technology Division, Argonne National Laboratory. The ferromagnetic particles were manufactured by CORTEX Company and washed with $0.02 \mathrm{~mm}$-filtered deionized water to eliminate any preservatives.

Extraction Process. Particle suspensions of $\sim 1$ wt $\%$ or less were contacted with hydrochloric acid, nitric acid, or simulant waste solutions containing ${ }^{241} \mathrm{Am}$ or ${ }^{238} \mathrm{Pu}$. Extraction and separation procedures are detailed in a previous publication. 11 An aliquot of each contacted solution was counted for alpha activity with a Packard 2200CA TRI-CARB liquid scintillation analyzer $\left({ }^{238} \mathrm{Pu}\right)$ or for gamma activity $\left({ }^{241} \mathrm{Am}\right)$ on a Packard Minaxi g Autogamma 5000 Series (three-inch NaI crystal detector). Mass balance calculations using the initial and final solution activity were used to determine partition coefficients $\left(\mathrm{K}_{\mathrm{d}}\right)$.

The partition coefficients $\left(\mathrm{K}_{\mathrm{d}}\right)$ are determined from

$$
K_{d}=\left(\frac{C_{i}-C_{f}}{C_{f}}\right) \times \frac{V}{m}
$$

where

$\mathrm{V}$ is the contact volume of the aqueous solution, in $\mathrm{mL}$

$\mathrm{m}$ is the mass of the particles, in $\mathrm{g}$

$\mathrm{C}_{i}$ is the initial stock solution counts before contact, in $\mathrm{cps} / \mathrm{mL}$

$\mathrm{C}_{\mathrm{f}}$ is the final solution counts after contact, in $\mathrm{cps} / \mathrm{mL}$

Distribution ratios for liquid-liquid contacts were also determined by

$$
\mathrm{D}=\frac{\text { activity in the organic phase }}{\text { activity in the aqueous phase }}
$$

Preparation of HLW Simulant. Various HLW simulants were used to test actinide removal with the MACS particles. The following simulants were tested: Hanford dissolved tank (SST) sludge, acid dissolved Hanford Plutonium Finishing Plant (PFP) waste, Hanford tank supernatant, and Idaho Chemical Processing Plant (ICPP) dissolved calcine. In addition, hydrochloric acid solutions were evaluated for possible applications of the MACS process to Rocky Flats Plant (RFP) waste. Table I shows the composition and ion concentrations of the HLW simulant solutions 
tested. All acid solutions were titrated by using a Metrohm 670 Autotitrator with a glass electrode containing $3 \mathrm{M} \mathrm{KCl}$.

Table I. Liquid Waste Simulants Prepared for MACS Process Testing

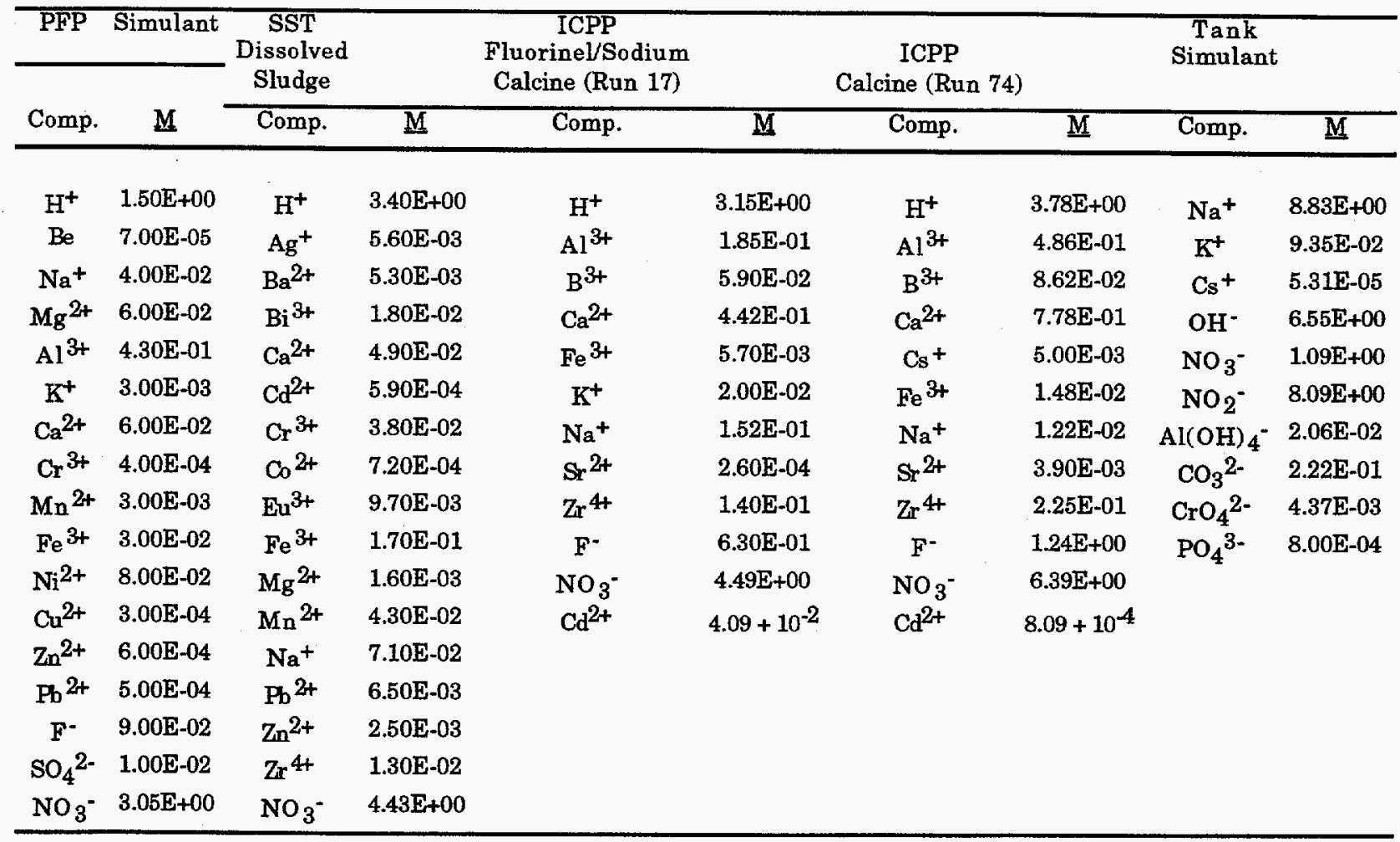

Microscopy, Electron Diffraction, and Electron Dispersive Spectroscopy (EDS). The MACS particle samples were prepared by ultramicrotomy for microscopic observation. First, a polyethylene BEEM ${ }^{\mathrm{TM}}$ capsule was filled with Medcast resin to a depth of approximately $1.5 \mathrm{~cm}$. The samples were sectioned on an ultramicrotomy with a diamond knife to a nominal thickness of $\sim 1000 \mathrm{~nm}$. The sections, upon leaving the diamond knife, were floated onto a bath of deionized water. Then they were placed upon a carbon film supported by a $3 \mathrm{~mm}$ copper grid. Samples were examined in a JEOL 2000FXII transmission electron microscope (TEM) at $200 \mathrm{kV}$; the variable aperture was removed for electron diffraction measurements. Samples that were suitable for electron dispersive spectroscopy (EDS) were examined in tandem, using a NORAN ultrathin window system in the horizontal port of the JEOL 2000. The morphology studies focused on gamma irradiation effects on the particles.

Gamma Radiolysis. The MACS particles were irradiated with a high intensity ${ }^{60} \mathrm{Co}$ gamma-ray source $(60,000 \mathrm{Ci})$ located at ANL. All particle samples were mixed with one of six testing 
solutions and vacuum sealed in quartz tubes. The sealed tubes were rotated end-over-end during irradiation and acquired the ambient air temperature of the ${ }^{60} \mathrm{Co}$ cell, approximately $30^{\circ} \mathrm{C}$. The average dose rate was between $1.1 \times 10^{5}$ and $2.2 \times 10^{5} \mathrm{rad} / \mathrm{h}$. The expected doses to the particles were estimated to determine the exposure time of the particles to the ${ }^{60} \mathrm{Co}$ source. The time required for an extraction, strip, and regeneration of particles for actinide elements was defined as one cycle for gamma dose calculations. Water equivalent dose rates were determined by measuring the change in optical density of blue cobalt glass. The water equivalent dose rate was multiplied by the ratio of the electron density of the particles to the electron density of water (2.3); this yielded the dose rate to the particles. Upon completion of the irradiations, the quartz vials were opened and the particles were separated from the contact solutions. The quartz vials containing particles in $5 \underline{\mathrm{M}} \mathrm{HNO}_{3}$ were sometimes coated with deposits of a sticky yellow organic material. The $\mathrm{K}_{\mathrm{d}}$ values of the irradiated particles were measured by using $2 \underline{\mathrm{M}} \mathrm{HNO}_{3}$ spiked with ${ }^{241} \mathrm{Am}$.

\section{Results and Discussion}

To compete with traditional solvent extraction, the $\mathrm{K}_{\mathbf{d}}$ values for the batch MACS process must be 1000 or greater. Particle separation capabilities were initially evaluated in nitric acid solutions. As shown in Table 2, the $\mathrm{K}_{\mathrm{d}}$ values obtained for actinide elements from the MACS process are high for $2 \mathrm{M}$ nitric acid solutions. Unfortunately, waste streams from many of the Hanford single shell tanks (SSTs) contain large concentrations of lanthanides (Ln) and other elements that may compete with the extraction of americium. Such lanthanide loading of the CMPO could complicate the actinide separation. Combining sludges from all the tanks yielded an average waste composition $^{5}$ (see Table 1) that could interfere with in situ MACS processing.

To monitor loading effects, we studied actinide separation from simulant solutions of several DOE HLW streams (characterized in Table 1) spiked with actinide tracer. Table 2 shows the $\mathrm{K}_{\mathrm{d}}$ values measured in the HLW simulant solutions. For the PFP $(\mathrm{Ox})^{*}$ waste, the average $\mathrm{K}_{\mathrm{d}}$ values for americium are greater than 1500 , while plutonium(IV) extracts with a $K_{d}$ of 18,000 . Because the concentrations of lanthanides and other interfering elements are low, actinide elements can be easily separated from the PFP feed stream. The plutonium experiments were modified by adding sufficient plutonium to achieve a $\mathrm{Ln} / \mathrm{Pu}$ ratio of about 300 (the expected $\mathrm{Ln} / \mathrm{Pu}$ ratio in SST waste); $\mathrm{K}_{\mathrm{d}}$ values of 2400 for plutonium were achieved. At higher $\mathrm{Ln} / \mathrm{Pu}$ ratios $\left(10^{8}\right)$, the actinide separation was negligible.

\footnotetext{
* Oxalate is added to the waste stream to complex the ferric ion, which can also complete with $\mathrm{Am}^{3+}$ for CMPO.
} 
Table 2. Partition Coefficients Determined for Various Simulant/Tracer Solutions with Ferromagnetic Particles

\begin{tabular}{|c|c|c|c|c|}
\hline Tracer & Solvent Type & HLW Simulant & $\overline{K_{\mathrm{d}}(\mathrm{mL} / \mathrm{g})}$ & $\overline{D_{\text {exp }}}$ \\
\hline $\mathrm{Am}$ & $1.2 \mathrm{M}$ CMPO & $2 \mathrm{M} \mathrm{HNO} 3$ & $4,000-5,000$ & 1,700 \\
\hline $\mathrm{Pu}$ & $1.2 \mathrm{M} \mathrm{CMPO}$ & $2 \mathrm{M} \mathrm{HNO}_{3}$ & 65,000 & - \\
\hline $\mathrm{Pu}$ & 1.0M CMPO & PFP & 18,000 & 1,400 \\
\hline $\mathrm{Am}$ & $1.0 \mathrm{M} \mathrm{CMPO}$ & PFP & 140 & - \\
\hline $\mathrm{Am}$ & 1.5M CMPO & $\operatorname{PFP}(\mathrm{Ox})$ & $1,500-4,000$ & - \\
\hline $\mathrm{Am}$ & $0.8 \mathrm{M}$ CMPO & $5.0 \underline{\mathrm{M} \mathrm{HCl}}$ & 23 & - \\
\hline $\mathrm{Pu}$ & 1.0M CMPO & $2.0 \mathrm{M} \mathrm{HCl}$ & 10 & - \\
\hline $\mathbf{P u}$ & $1.0 \mathrm{M}$ CMPO & $5.0 \mathrm{M} \mathrm{HCl}$ & 560 & - \\
\hline $\mathbf{P u}$ & 1.0M CMPO & $8.0 \mathrm{M} \mathrm{HCl}$ & 26,000 & 1,600 \\
\hline $\mathrm{Am}$ & $0.8 \mathrm{M}$ CMPO & SST Cs Supernatant & $7,000-16,000$ & - \\
\hline $\mathrm{Pu}$ & 1.2M CMPO & SST Cs Supernatant & 20,000 & - \\
\hline $\mathrm{Am}$ & 1.5M CMPO & SST Dissolved Sludge & 2 & - \\
\hline $\mathrm{Pu}$ & $1.0 \mathrm{M}$ CMPO & SST Dissolved Sludge & 2,400 & - \\
\hline $\mathrm{Pu}$ & $0.58 \mathrm{M}$ CMPO & SST Supernatant & $14,000-40,000$ & 8,800 \\
\hline Am & $0.58 \mathrm{M}$ CMPO & ICPP Run 17 Calcine ${ }^{\dagger}$ & $0^{*}$ & - \\
\hline Am & $0.58 \underline{\mathrm{M}} \mathrm{CMPO}$ & ICPP Run 74 Calcine $\mathrm{f}^{\dagger}$ & $0^{*}$ & - \\
\hline
\end{tabular}

The basic supernatant in the tanks at Hanford contains radioactive cesium and technetium, as well as a small fraction of strontium and actinides, which must be separated. Transuranics were easily removed from the Hanford supernatant simulant. The $\mathrm{K}_{\mathrm{d}}$ values for americium and plutonium exceeded 7,000 and 20,000 , respectively, although problems with tracer stability occurred because the simulant was a basic solution. The reasons given for large separation in basic solution are two-fold: (1) the uncoated magnetite can activate in basic solution and absorb actinides, 12 and (2) the high nitrate concentration favors the separation of the actinide complex with CMPO.

The process waste stream expected to be treated at RFP originates from direct oxide reduction of plutonium and is a high ionic strength $\mathrm{KCl} / \mathrm{HCl}$ solution. For the RFP waste the average $K_{d}$ values for $A m$ and $P u$ were 23 and 26,000, respectively, in $5 M$ and $8 \mathrm{M} H C l$. This extraction is possible due to the high chloride ionic strength in the waste solution. 13 
The ICPP/Run 17 calcine is rich in fluoride and sodium, while the Run 74 calcine is rich in zirconium from the fuel cladding. The preliminary results from ICPP/Run 17 and Run 74 calcine wastes gave $\mathrm{K}_{\mathrm{d}}$ values for both $\mathrm{Am}$ and $\mathrm{Pu}$ close to zero. Some chemical interference from fluoride and zirconium can possibly limit the extractability of the actinides.

The results obtained suggest that the MACS process can be applied to remediate waste streams at the Hanford Site and other waste with low concentrations of actinide elements. However, MACS process has limitations at high concentrations of actinide and/or with the presence of interfering elements and is not effective with waste streams such as dissolved sludge and ICPP calcine waste. In such situations, conventional solvent extraction or ion exchange techniques may be more applicable. A comparison of the $\mathrm{K}_{\mathrm{d}}$ values with the solvent extraction distribution ratios $\left(D_{\text {exp }}\right)$ in Table 2 indicates that the MACS particles exhibit a synergistic effect between the particle surface and the extractants; this synergism enhances the separation for actinides. Conversion of a $\mathrm{D}$ value to a $K_{d}$ value is done by multiplying the $D$ value by the milliliters of solvent per gram of particles (which is $\sim 0.3 \mathrm{~mL} / \mathrm{g}$ ). The $\mathrm{K}_{\mathrm{d}}$ values are $3-50$ times higher than the $D$ values, thereby emphasizing the efficiency of extraction using magnetic microparticles. For example, the $\mathrm{D}$ value for americium extraction in $2 \underline{\mathrm{M}} \mathrm{HNO}_{3}$ would have to exceed $10^{5}$ in order to display equivalent extraction efficiency to the magnetic particles.

Gamma Radiolysis. The particles must be chemically and physically durable during HLW treatment. A gamma radiolysis study was undertaken to determine the radiation effects under various acidic conditions.

The ability of the MACS particles to extract americium from $2 \underline{\mathrm{M}} \mathrm{HNO}_{3}$ solutions depends on the radiation dose, composition of solution contacting the particles during irradiation, and radiation/contact time. Figure 2 depicts the variation in the $\mathrm{K}_{\mathrm{d}}$ value for absorbed doses equivalent to 10 cycles ( $0.013 \mathrm{Mrad}), 100$ cycles ( $0.14 \mathrm{Mrad}$ ), and 2000 cycles ( $3.1 \mathrm{Mrad})$ of use. The decline in extraction capacity with increase in dose is most prevalent with the higher nitric acid concentrations. The $\mathrm{K}_{\mathrm{d}}$ values at $0.001 \mathrm{Mrad}$ are for particles exposed for five hours but not irradiated. Based on the slight decrease in extraction capacity of the $0.1 \mathrm{M} \mathrm{HNO}_{3}$, it appears that the $\mathrm{HNO}_{3}$ concentration in the contact solutions is responsible for most of the decline in $\mathrm{K}_{\mathrm{d}}$ values. Figure 3 shows the change in $K_{d}$ value with contact time in $0.1,2$, and $5 \underline{M} \mathrm{HNO}_{3}$. The sharp drop in extraction capability for particles in contact with $5 \underline{\mathrm{M}} \mathrm{HNO}_{3}$ and the deposits of sticky, yellow organic found inside the contact tubes suggest that the acid may be dissolving the magnetite. 


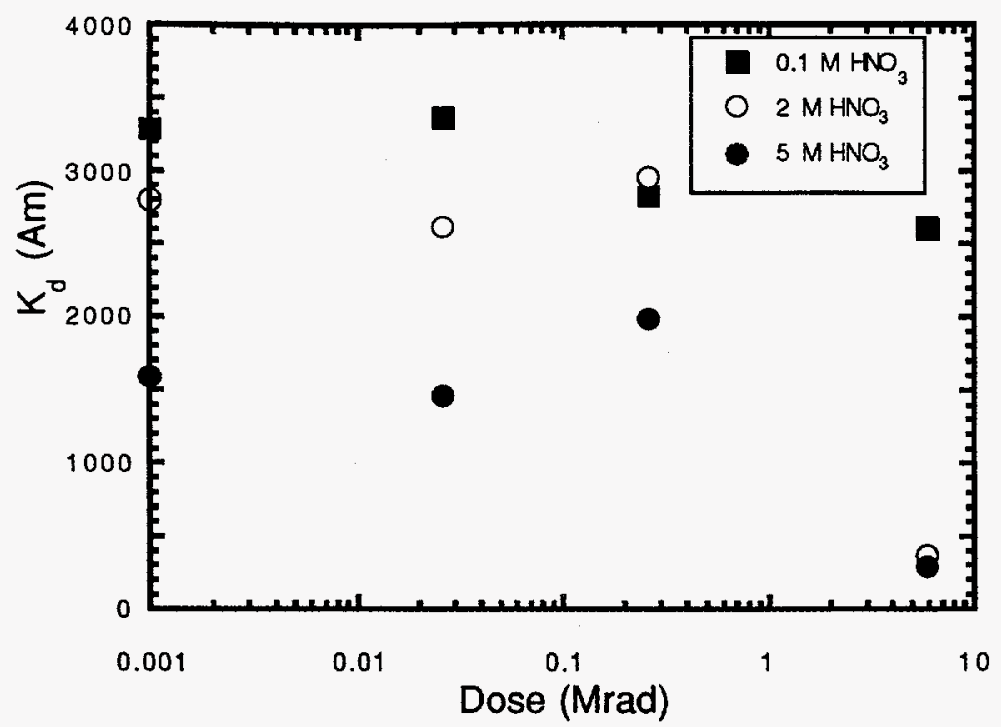

Figure 2. Change in $K_{d}(A m)$ Values with Absorbed Dose and Nitric Acid Concentration in the Contact Solutions. Particles coated with 1.36M CMPO in TBP. All $\mathrm{K}_{\mathrm{d}}$ values measured with ${ }^{241} \mathrm{Am}$ in $2 \mathrm{M}$ HNO 3 .

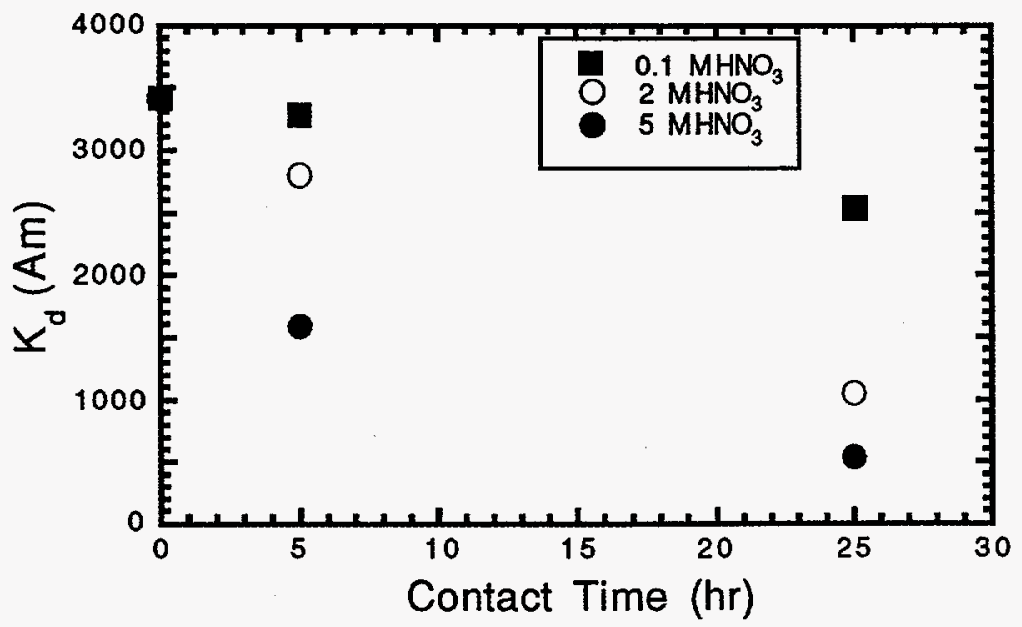

Figure 3. Change in $K_{d}(A m)$ Values with Contact Time and Nitric Acid Concentration in the Contact Solutions. Particles coated with 1.36M CMPO in TBP. All $\mathrm{K}_{\mathrm{d}}$ values measured with ${ }^{241} \mathrm{Am}$ in $2 \mathrm{M} \mathrm{HNO}_{3}$.

Microscopy, Electron Diffraction, and Electron Dispersive Spectroscopy (EDS). The particles were irradiated in simulated PFP waste for $0,10,100$, and 2000 cycle exposure periods (see Figures 4a-4d). All of the particles exhibited some radiation damage. The damage appeared as a fine-mottled structure with increased contrast over undamaged polymer. With increased 
radiation dose and subsequent damage, the polymer morphology began to take on a fine needle-like structure. With further gamma irradiation, pitting regions in the polymer were apparent. The entire polymeric region was not damaged, indicating that this pitting is a real effect and not an artifact generated by the microscope. The micrograph contained both damaged and relatively undamaged polymer regions. The amount of undamaged material declined as radiation dose increased.

Further evidence of damage to the polymer was its embrittlement with radiation exposure. This embrittlement has caused the polymers to chatter parallel to the direction of the knife blade. This chattering is similar to that seen in ultramicrotomed glass samples. Notice that in none of the micrographs did the Medcast chatter, nor was any chattering evident in the study done on the non-irradiated samples worked on previously. 12 The polymer also was examined with electron diffraction and EDS to determine damage and the absorbed extractants.

At least some of the damaged polymer was found to contain short-range order, observed as rings in the electron diffraction pattern. An amorphous material does not effectively diffract the electron beam to produce a diffraction pattern, but produces a diffuse core around the transmitted beam. Experiments were undertaken to determine if the relative crystallinity of the polymer increased with increased radiation exposure. Three different large areas of particles were examined. The beam current and current density were kept the same for all of the samples. Each diffraction pattern was recorded twice, using 8- and 11-s exposure times. No visible systematic quantitative changes were observed on the diffraction pattern negatives among the different samples. Some differences were observed within each sample set, but this could be a result of thickness variations in the polymer coating and/or the supporting carbon film.

A long-term ( $>1 \mathrm{~h}$ ) EDS spectrum was taken on a large area of coating to determine which trace elements could be detected. The coating spectrum contained, in order of descending peak height (which is proportional to the concentration): $\mathrm{Fe}, \mathrm{Al}, \mathrm{Si}, \mathrm{Cl}, \mathrm{S}, \mathrm{P}, \mathrm{Ca}, \mathrm{Na}, \mathrm{Mn}$, and $\mathrm{Pb}$. Sodium was also present but was not quantified due to the low sensitivity to this element. A large copper peak was an artifact due to fluorescence in the microscope column. The presence of silicone was unexpected since it was not present in the complexing PFP solution. It could be an artifact from glassware dissolution by HF, since it is present in relatively large amounts in most of the coatings examined. There does appear to be a decrease in the relative amount of phosphorus in the coatings with increasing radiation dose. This is consistent with the removal of organophosphorus extractants from the coating by irradiation damage. 


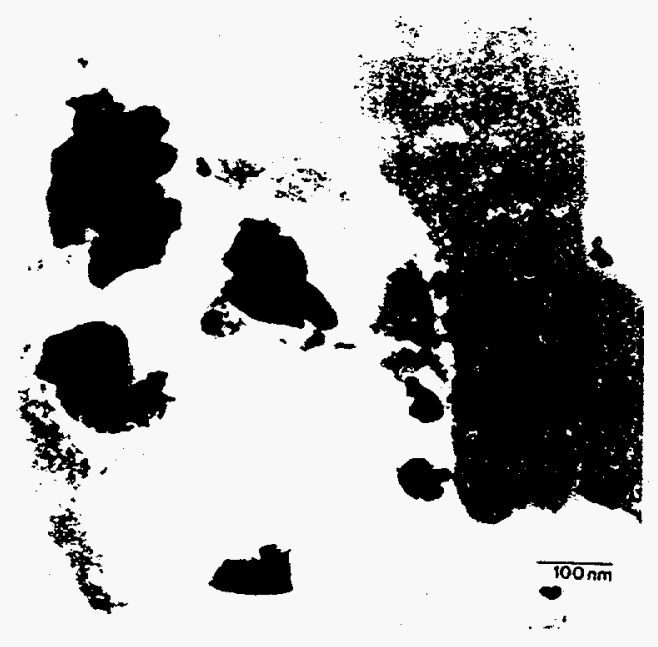

(a)
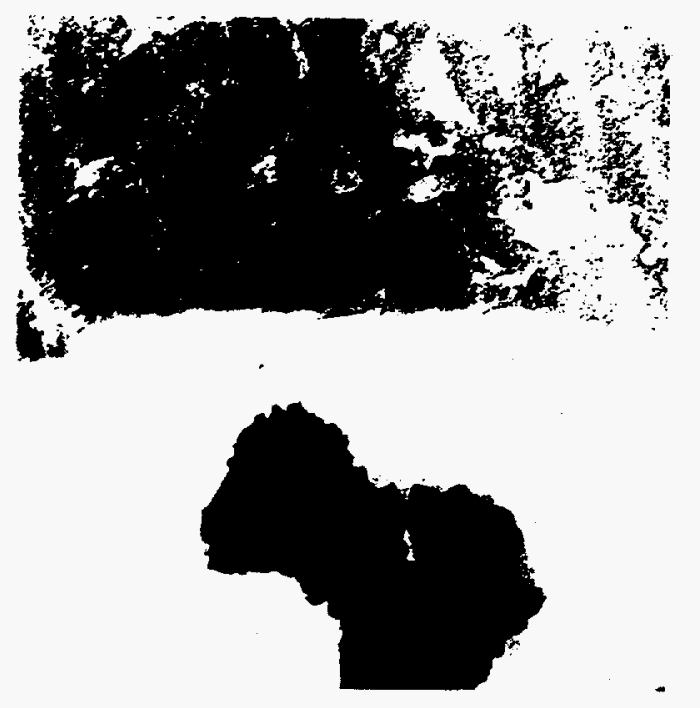

(c)

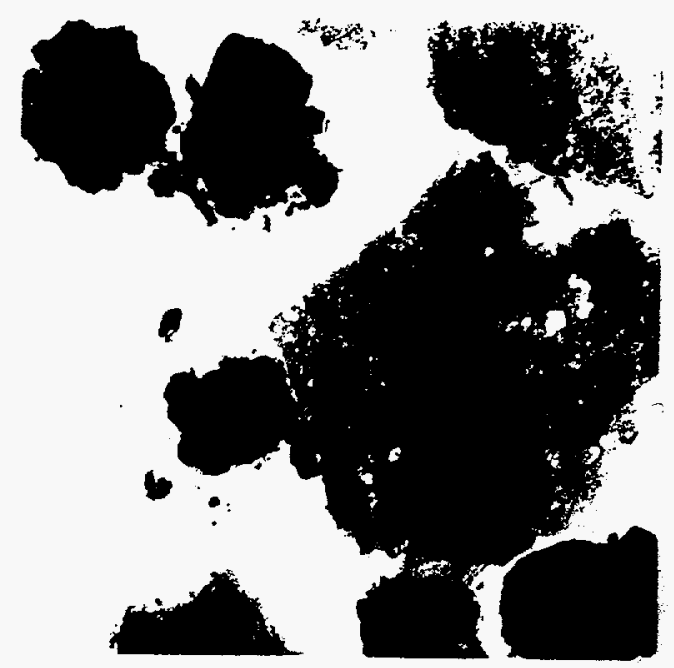

(b)

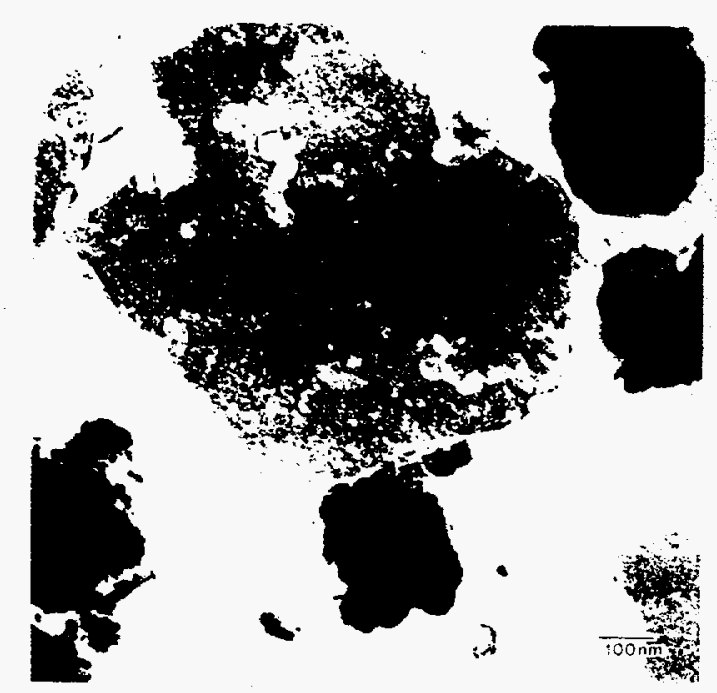

(d)

Figure 4. (a) MACS particles with no irradiation. Black regions are magnetite and dark gray regions are polymer. (b) $0.013 \mathrm{Mrad}$ (10 cycle) in PFP simulant. High magnification micrograph of large particle and polymer. The coating in the upper right-hand corner of the micrograph is relatively undamaged. (c) $0.14 \mathrm{Mrad}$ (100 cycle) in PFP simulant. Chattering along the knife path is noted. The polymeric region displayed needle-like damage with some pitting. Also, the damage contrast is greater than in less damaged samples. (d) $3.1 \mathrm{Mrad}$ (2000 cycles) in PFP simulant. Pitting of the polymer is extensive. 
Three or more long-term spectra were acquired for each of the samples. The peak heights were compared to determine if the decrease in phosphorus levels was statistically valid. Elemental concentrations were quantified by using the NORAN EDS standards program. There was a wide variation in the $\mathrm{Al}$ and $\mathrm{Mg}$ contents of the coatings. Surprisingly, the element with the least variation was silicon, which is presumably an artifact from the glassware. The second column in Table 3 gives the atomic \% phosphorus (normalized to $100 \%$ for all elements analyzed, except for $\mathrm{C}$ and $\mathrm{Na}$ ), including standard deviation (SD). The third and fourth columns are the ratios of the total counts under the element peaks. The lack of a systematic trend in the percent phosphorus reduction is probably due to radiation damage inhomogeneity, as indicated by Table 3 and Figure 4a-d, and the high standard deviation for the high radiation dose.

Table 3. Relative Phosphorus Concentration in Polymer of MACS Particles as Function of Radiation Dose

\begin{tabular}{lcll}
\hline Dose (Mrad) & $\% \mathrm{P}(\mathrm{SD})^{*}$ & $\mathrm{P} / \mathrm{Si}(\mathrm{SD})$ & $\mathrm{Fe} / \mathrm{P}(\mathrm{SD})^{\dagger}$ \\
\hline & & & \\
0.013 & $43.4(5.2)$ & $1.20(0.2)$ & $5.0(2.5)$ \\
0.14 & $4.4(1.6)$ & $0.17(0.04)$ & $0.31(0.2)$ \\
3.1 & $5.0(2.4)$ & $0.16(0.1)$ & $1.2(0.6)$ \\
\hline
\end{tabular}

* Normalized for elements detected.

$\dagger$ Iron absorbed on polymer surface.

\section{Summary}

The MACS process is an efficient and compact separation technology that employs organophosphorus extractants absorbed on magnetic microparticles. The large $\mathrm{K}_{\mathbf{d}}$ values obtained for plutonium and americium for some HLW streams illustrate that the MACS process will achieve higher efficiency separations than possible with traditional liquid/liquid extraction processes for similar simulants. Preliminary design for an MSFB unit is currently underway for testing simulant waste. The gamma irradiation study and subsequent analysis by TEM, electron diffraction, and EDS showed qualitatively that both the polymer and absorbed extractants suffered radiation damage and degradation. The damage was more severe with larger absorbed doses and longer exposure to acidic conditions. Specifically, the particles were more susceptible to damage from acid degradation than gamma radiolysis.

\section{Acknowledgments}

This work is supported by the U.S. Department of Energy under Efficient Separation Processes Integrated Program (ESPIP), Contract W-31-109-Eng-38. 


\section{Reference}

1. G. F. Vandegrift, R. A. Leonard, M. J. Steindler, E. P. Horwitz, L. T. Basile, H. Diamond, D. G. Kalina, and L. Kaplan, "Transuranic Decontamination of Nitric Acid Solution by the TRUEX Solvent Extraction Process--Preliminary Development Studies," Argonne National Laboratory report, ANL-84-45 (1984).

2. L. E. Trevorrow, and G. F. Vandegrift, "Alternatives for Disposal of Raffinate from the TRUEX Process," Argonne National Laboratory report, ANL-89-27 (1989).

3. D. B. Chamberlain and R. A. Leonard, "TRUEX Hot Demonstration: Final Report," Argonne National Laboratory report, ANL-89-37 (1989).

4. G. F. Vandegrift, D. B. Chamberlain, C. Conner, J. M. Copple, J. A. Dow, L. Everson, J. C. Hutter, R. A. Leonard, L. Nuñez, J. M. Copple, J. A. Dow, B. Srinivasan, M. C. Regalbuto, and S. Weber, "Development and Demonstration of the TRUEX Solvent Extraction Process," Proceedings of WM Symposia, Tuscon, AZ, (1993).

5. J. L. Straalsund, J. L. Swanson, E. G. Baker, J. J. Holmes, E. O. Jones, and W. L. Kuhn, "Clean Option: An Alternative Strategy for Hanford Tank Waste Remediation," Pacific Northwest Laboratory report PNL-8388, Vol. 1 (1992).

6. L. Nuñez, B. A. Buchholz, and G. F. Vandegrift, submitted to: Proceedings of the Eighth Symposium on Separation Science and Technology, Gatlinburg, TN (1993).

7. G. Dupre, J. Pirkle, and J. Siegell, Chromatographic Separations in a Crossflow Magnetically Stabilized Bed, Exxon Research and Engineering Company, Florham Park, $\mathrm{NJ}$ (1986).

8. M. Burns and D. Putnam, A Microscopic Study of Particle Filtration in a Magnetically Stabilized Fluidized Bed, University of Michigan, Ann Arbor, MI (1992).

9. W. L. McCabe, J. C. Smith, and P. Harriot, Transport Phenomena, McGraw-Hill, New York (1993).

10. D. C. Chaiko, P. K. Tse, and G. F. Vandegrift, "Modeling of the Aqueous and Organic Phase Speciation for Solvent Extraction Systems," Minerals, Metals, \& Materials Soc., Warrendale, PA, pp. 261-272 (1988).

11. L. Nuñez and G. F. Vandegrift, "Plutonium and Americium Separation Using Organophosphorus Extractants Absorbed onto Ferromagnetic Particles, F-Elements Separation," proceedings from ACS March 1994 Meeting in San Diego, CA, to be published, (1994).

12. R. Kochen, Actinide Removal from Aqueous Solution with Activated Magnetite, Rocky Flats Plant report RFP-4100 (1987).

13. E. P. Horwitz, H. Diamond, and K. A. Martin, "The Extraction of Selected Actinides in the (III), (IV), and (VI) Oxidation States from Hydrochloric Acid by OfD(iB)CMPO: The TRUEX--Chloride Process," Solvent Extraction and Ion Exchange, 5(3), 447-470 (1987). 